\title{
Commentary Circumspectives: Cannabis and Psychiatric Illness: Blunt Thoughts
}

\author{
Markus Heilig*,I and William A Carlezon $^{2}$ \\ 'Center for Social and Affective Neuroscience, Department of Clinical and Experimental Medicine, Linköping University, Linköping, Sweden; \\ ${ }^{2}$ Harvard Medical School, McLean Hospital, Belmont, MA USA
}

Neuropsychopharmacology (2016) 4I, 39I-392; doi: I0.1038/npp.2015.32I; published online II November 2015

The journal is now publishing its Circumspectives feature at a pace of approximately two per year. Recognizable by their special cover designs, the purpose of Circumspectives articles is to consider an issue from multiple perspectives, with separate sections in which two thought leaders articulate their individual positions on a topic of great importance to our community of researchers. The distinguishing element, however, is that each piece ends with a reconciliation that is co-authored by both and includes ideas or experiments to move the field forward. Although originally envisioned as a forum for debates, the individual articles we have received have shown a rapid and appealing evolution. In addition to a 'debate', we have now had features that can be broadly conceptualized as 'hopes versus hurdles', 'advantages versus disadvantages', and 'known versus unknown'. All fulfill the basic premise of looking at issues from at least two perspectives. They are also intended to contain key references on the subject matter, making them convenient source material.

Our most recent article is entitled 'Does cannabis cause, exacerbate or ameliorate psychiatric disorders? An oversimplified debate discussed', jointly authored by Margaret (Meg) Haney and Eden Evins. These authors take on the timely and thorny issue of whether cannabis or its constituents do more-or less-harm than good. Few issues with an impact on public health are more polarizing. Major shifts in public opinion and policy are currently underway in the US to decriminalize or outright legalize cannabis use. Individual states now stake out their own course on this issue, despite the fact that federal law continues to consider it illegal to possess, use, buy, sell, or cultivate marijuana under the Controlled Substances Act of 1970. Internationally, policy positions run the spectrum of a long history of de facto legalization in some countries (eg, Holland) to a continued illicit status, with considerable deterrence efforts (eg, Sweden and Norway). Remarkably, and of particular interest for the readers of this journal, these policy positions are largely

\footnotetext{
*Correspondence: Dr M Heilig, Center for Social and Affective Neuroscience, Department of Clinical and Experimental Medicine, Linköping University, Linköping, Sweden,
}

Tel: +46 132866 26, Fax: +46 ( I0) 103 3393, E-mail: markus.heilig@liu.se argued in a manner disconnected from the considerable body of scientific data available to inform them.

The authors of the current Circumspectives have contributed important elements of that science, and are ideally positioned to provide a scientific basis to inform the debate. In an area as broad and as polarizing as this one, it might be hard to find approaches that are stringent and yet still provide broad insights on the big picture issues. Drs. Haney and Evins have accomplished both of these goals. The key to their article is that they selected two very specific and critical questions at the forefront of the debate: first, what is the evidence that cannabis is beneficial or harmful in posttraumatic stress disorder (PTSD)?; and second, how strong is the evidence to support a link between cannabis use and psychosis risk?

The first question, which focuses on the benefits or harms of cannabis use in PTSD, is exceptionally timely. PTSD is found in more than $13 \%$ of armed forces members deployed in a combat role in the conflicts in Iraq and Afghanistan, and only a minority of these veterans seek or receive professional treatment (Hoge et al, 2014). This adds to the incidence of PTSD that stems from domestic causes, among which rape, sexual violence, and intimate partner violence are predominant, resulting in PTSD rates in women being twice those in men (Kessler et al, 1995). Anecdotes abound of the beneficial effects of cannabis use as a self-medication in PTSD, as do stories of adverse effects. These conflicting reports tie into an emerging realization that endocannabinoid systems are critically important for regulating stress responses, and indeed might offer novel therapeutic targets in PTSD (Neumeister et al, 2015). The question is whether blunt pharmacological actions such as global brain CB1 receptor activation, as occurs with cannabis use, might be beneficial, safe, and well tolerated. Although that possibility cannot be excluded, it is conceivable that more refined interventions, such as potentiating fear extinction through inhibition of endocannabinoid-degrading enzymes, might be required (Gunduz-Cinar et al, 2013).

The latter question, of a possible association between cannabis use and psychotic illness, was brought to the fore by classical epidemiological observations made almost 30 years 
ago (Andreasson et al, 1987). The most common psychotic disorder, schizophrenia, has a high heritability and a long duration of a prodromal stage that typically precedes a diagnosis. Because of this, it becomes exceptionally challenging to establish the direction of cause-effect relationships, if at all present. It seems clear that schizophrenia and cannabis use occur together considerably more than might be attributed to chance. The question is whether this represents a shared vulnerability for both conditions, a situation in which prodromal psychosis symptoms cause an increased risk of cannabis use intended as self-medication, or one in which cannabis use indeed contributes to elevated risk for schizophrenia. Drs. Haney and Evins objectively describe the strengths and weaknesses in data at different levels of explanation-epidemiology, clinical, and genetic-that have been advanced to support or refute the different types of links postulated. An important conclusion that can be drawn from their discussion is that the connection is far from clear and well-understood, which differs from the narrative championed by some of the most outspoken voices in the public debate.

It is important to note that cannabis use, be it recreational or medicinal, is now a highly politicized issue. The editors are grateful to Dr Haney and Dr Evins for having the courage to put their ideas down on paper so they can be discussed in a way that will lead us closer to the truth. We welcome suggestions for future Circumspectives topics and authors, which can be submitted to journal@acnp.org. Please note that articles of this type submitted without pre-approval will not be considered. Our next one is scheduled to appear in mid-2016.

\section{FUNDING AND DISCLOSURE}

The authors declare no competing interests.

\section{REFERENCES}

Andreasson S, Allebeck P, Engstrom A, Rydberg U (1987). Cannabis and schizophrenia. A longitudinal study of Swedish conscripts. Lancet 2: 1483-1486.

Gunduz-Cinar O, Macpherson KP, Cinar R, Gamble-George J, Sugden K, Williams B et al (2013). Convergent translational evidence of a role for anandamide in amygdala-mediated fear extinction, threat processing and stress-reactivity. Mol Psychiatry 18: 813-823.

Haney M, Evins AE (2015). Does cannabis cause, exacerbate or ameliorate psychiatric illness? An oversimplified debate discussed. Neuropsychopharmacol (this issue).

Hoge CW, Grossman SH, Auchterlonie JL, Riviere LA, Milliken CS, Wilk JE (2014). PTSD treatment for soldiers after combat deployment: low utilization of mental health care and reasons for dropout. Psychiatr Serv 65: 997-1004.

Kessler RC, Sonnega A, Bromet E, Hughes M, Nelson CB (1995). Posttraumatic stress disorder in the National Comorbidity Survey. Arch Gen Psychiatry 52: 1048-1060.

Neumeister A, Seidel J, Ragen BJ, Pietrzak RH (2015). Translational evidence for a role of endocannabinoids in the etiology and treatment of posttraumatic stress disorder. Psychoneuroendocrinology 51: 577-584. 